\title{
Análise do Conhecimento sobre DSTs e PLANejamento familiar ENTRE DEFICIENTES AUDITIVOS E OUVINTES DE UMA ESCOLA PÚBLICA DE FORTALEZA
}

\author{
ANALYSIS OF KNOWLEDGE OF STDS AND FAMILY PLANNING AMONG PEOPLE \\ WITH AND WITHOUT HEARING-IM PAIRMENT AT A PUBLIC SCHOOL IN FORTALEZA
}

\author{
Tadeu Rodriguez de Carvalho PINHEIRO FILHO ${ }^{1}$ \\ José Cláudio Borges da SILVA FILHO² \\ Emilcy Rebouças GONÇALVES 3 \\ A manda Maria Menezes DANTAS ${ }^{4}$ \\ Silvia Bomfim HYPPÓLITO5
}

\begin{abstract}
RESUM O : segundo a OMS, havia cerca de 278 mil hões de deficientes auditivos no mundo, em 2005. A maioria deles não tem acesso a serviços de educação em saúde sexual, o que os tornam bastantevulneráveis a ocorrência de gravidez precoce e infecção por Doenças Sexualmente Transmissíveis (DSTs)/ AIDS. Objetivou-se analisar comparativamente o conhecimento de estudantes, com ou sem alguma deficiência auditiva, de uma escola pública, sobre planejamento familiar e DSTs. Trata-se de um estudo transversal e comparativo em que 149 estudantes de uma escola pública foram divididos em 2 grupos: 98 ouvintes e 51 não-ouvintes. Foi então aplicado um questionário com indagações sobre planejamento familiar e DSTs. Os dados foram analisados pelo programaEPI INFO, considerando p válido quando <0,05. Resultados: 50,00\% dos não-ouvintes referiram existir cura para AIDS contra $25,30 \%$ dos ouvintes; $92,90 \%$ dos ouvintes relataram que uso de preservativo protege contra AIDS/ DST's, contra $43,10 \%$ dos não ouvintes. A maioria dos ouvintes, $97,90 \%$, afirmou que procuraria um serviço de saúde caso alguma lesão típica de DSTs se manifestasse, contra $47,10 \%$ dos nãoouvintes. Os dados apresentados inferem que há uma carência de informação acerca destes temas entre a população jovem com deficiência auditiva.
\end{abstract}

PALAVRAS-CHAVE: educação especial; deficiente da audição; doenças sexualmente transmissíveis; planejamento familiar.

\footnotetext{
${ }^{1}$ Graduando do 9o semestre de M edicina da Universidade Federal do Ceará. tadeurodriguezp@yahoo.com.br ${ }^{2}$ Graduando do 30 semestre de Medicina da Universidade Federal do Ceará. -claudinho_15cf@hotmail.com ${ }^{3}$ Graduanda do 70 semestre de Medicina da Universidade Federal do Ceará- emilcyreb@gmail.com

${ }^{4}$ Graduanda do 7ㅇsemestre de M edicina da Universidade Federal do Ceará. -amanda_mdantas@hotmail.com ${ }^{5}$ Doutora em Tocoginecologia, Professora do Departamento de Saúde Materno-Infantil da Universidade Federal do Ceará, Orientadora da Liga de Estudos em Ginecologia e Obstetrícia, Coordenadora do Núcleo de Estudos em Saúde Reprodutiva (NESAR) da Maternidade Escola Assis Chateaubriand, Coordenadora de Programas A cadêmicos e Vice-Diretora da Faculdade de Medicina da Universidade Federal do Ceará.silviabh@secrel.com.br
} 
A BSTRACT : According to the WHO, there were close to 278 million deaf people in the world in 2005 . Most of them have no access to education services related to sex education, which makes them quite vulnerable to early pregnancy and infection by sexually transmitted diseases (STDs)/ AIDS. This study aimed to analyze the knowledge public school students with and without hearing impairment, had about family planning and STDs. This is a cross-sectional comparative study in which 149 students from a public school were divided into 2 groups: 98 hearing students and 51 deaf students. They answered a questionnaire with questions about family planning and STDs. The data were analyzed using EPI INFO and considered significant when $p<0.05$. Results: $50.00 \%$ of the deaf students answered that there is a cure for AIDS against $25.30 \%$ of the hearing students; $92.90 \%$ of hearing students while $43.10 \%$ of the deaf students reported that condom use protects against A IDS/ STDs. The majority of the hearing students (97.90\%) said they would go to a health clinic if an injury typical of sexually transmitted diseases appeared, against $47.10 \%$ of the deaf students. The data presented suggest that there is a lack of information about this subject content among young people with hearing impairments.

KEYWORDS: Special Education; Deaf students; Sexually Transmitted Disease; Family Planning.

\section{InTRODUÇÃo}

A bordar temáticas relacionadas à sexualidade, planejamento familiar e prevenção de Doenças Sexualmente Transmissíveis (DSTs) e AIDS com adolescentes e adultos jovens nem sempre tem sido uma tarefa fácil para profissionais da saúde, educadores efamiliares. Quando se trata, então, de jovens portadores de deficiência auditiva, a abordagem torna-se ainda mais complicada, mas não menos necessária. A incidência de HIV/ AIDS e DSTs nessa população é um fato concreto e já comprovado em algumas pesquisas (BARES, 1992 apud PEINKOFER, 1994), o que nos impulsiona a procurar entender os fatores que os tornam tão suscetíveis a riscos.

Segundo estimativa da Organização Mundial deSaúde(OMS), em 2005 havia no mundo cerca de 278 milhões de deficientes auditivos degraus moderado a profundo, dos quais $80 \%$ vivem em países subdesenvolvidos ou em desenvolvimento (OMS, 2006). No Brasil, essa população era de 5,75 milhões em 2000, cerca de $2 \%$ dos brasileiros (IBGE, 2000).

No Brasil, a assistência a pessoas com deficiência auditiva teve início em meados do século XIX, com a criação do Instituto dos Surdos Mudos, no Rio de Janeiro (BRASI L, 2007). Desdeentão, atéa década de1980, muitas outras instituições de ensino, al gumas inclusive em caráter de internato, foram criadas para atender surdos, constituindo as instituições de educação especial (MAZZOTTA, 1996, p. 3538). Esse período foi marcado por intensa exclusão dos deficientes auditivos por parte da sociedade, a qual os considerava indivíduos incapazes e que fugiam aos padrões homogêneos exigidos em todos os meios de convívio social.

A partir da década de 1980, iniciou-seo processo de inclusão dos surdos à sociedade, ainda em fase de implantação até os dias de hoje. Acredita-se no princípio de que as famílias e a sociedade devem adequar-se às necessidades dos deficientes e integrá-los aos diferentes meios, pois são pessoas capazes de 
desenvolverem, com autonomia eliberdade, a sua cidadania, assim como qualquer outra pessoa, portadora ou não de deficiência. Os deficientes auditivos possuem, assim, direitos a exigirem e deveres a cumprirem. (CHAVEIRO; BARBOSA, 2005)

A atual Lei de Diretrizes e Bases da Educação Nacional (Lei no 9.394/ 96) assegura, em seu 590 artigo, o acesso dos alunos com deficiência a currículos, métodos, técnicas e recursos educativos que atendam às suas necessidades, bem como professores com especialização adequada em nível médio ou superior, para o atendimento especializado (BRASIL, 1996). Além disso, a Língua Brasileira de Sinais (Libras), como meio legal de comunicação e expressão da comunidadesurda, foi instituída pela Lei Federal no 10.436, de 24 de abril de 2002, fornecendo respaldo institucional às garantias individuais e ao pleno exercício da cidadania dos surdos.

Dessa lei, vale destacar:

Art. 2 o Deve ser garantido, por parte do poder público em geral e empresas concessionárias de serviços públicos, formas institucionalizadas de apoiar o uso e difusão da Língua Brasileira deSinais - Libras como meio decomunicação objetiva e de utilização corrente das comunidades surdas do Brasil.

Art. 3oAs instituições públicas eempresas concessionárias deserviços públicos de assistência à saúde devem garantir atendimento e tratamento adequado aos portadores de deficiência auditiva, de acordo com as normas legais em vigor (BRASIL, 2002).

Vê-se, no entanto, que mesmo com a institucionalização da Libras como a língua oficial dos surdos no Brasil e com todas as providências que têm sido tomadas no sentido de promover o processo de inclusão, infelizmente, não seconseguiu minimizar as diversas limitações ainda hoje sofridas pel os deficientes auditivos. Dentre elas, podemos citar: a barreira da comunicação, uma vez que é restrito o uso de Libras apenas entre os surdos, sendo mínima a utilização da língua na comunicação surdo-ouvinte; a barreira cultural, como no caso de pais ouvintes que negam a surdez dos filhos; e o isolamento pela sociedade, por considerá-los incapazes ou vulneráveis (GASKINS, 1999).

Dentre os jovens surdos, especificamente, pode-se observar que o imaginário popular ainda constrói uma visão estigmatizante, queos considera como pessoas que possuem um adolescer diferente (retardado ou mesmo ausente) dos outros jovens, revestindo essa importante etapa do desenvolvimento sexual de mitos e tabus (CHAVEIRO; BARBOSA, 2005; SANTOS, 2003). Contudo, a sexualidade possui conceito vasto, que envolvevárias dimensões do ser humano e que deve ser respeitada e vivenciada como direito intrínseco de todos. Loyola e Caval canti (1990 apu d CURSIN O et al. 2006) afirmam que a conduta sexual, como uma forma de expressão da sexualidade, jamais deve limitar-se a um comportamento estereotipado, devendo transpor barreiras equebrar os limites da genitalidade. Assim, os jovens com deficiência têm interesse em sexo e sentem desejo e prazer, bem como se expõem a riscos, como quaisquer outros. 
No entanto, toda essa mitificação construída em cima da sexualidade dos surdos col oca-os à margem da educação sexual, seja pel os familiares, seja pela escola, seja pelos profissionais da saúde. Bento e Bueno (2005) citam que o INES (Instituto Nacional de Educação dos Surdos) fornece a orientação de que os pais devem ser os responsáveis pela educação e orientação sexual dos jovens surdos, al go bastanteraro na nossa reali idade. Loyola eCavalcanti (1990 apud CURSIN O et al. 2006) afirmam, ainda, que é fundamental o papel de educadores na desmistificação dos tabus que teimam em impor limites à sexualidade humana.

Abdo (2004apud BENTO; BUENO, 2005) afirma queas principais fontes de informações sobre sexo advêm de livros e revistas, parceiros, amigos, tel evisão e, entre as mulheres, médico. Dentre os surdos, predomina o compartilhamento informal deconhecimento pel o grupo, o que pode representar um risco, na medida em que permite a construção e o compartilhamento de mitos e informações equivocadas como verdades e fatos (GASKINS, 1999), podendo favorecer o surgimento de práticas sexuais arriscadas.

Com isso, a comunicação do profissional desaúdecom os surdos surge como um desafio, pois esta se estabel ece como um fator essencial para a qual idade dos serviços prestados a esse grupo, principal mente aquel es relacionados à saúde sexual. Para Bicudo (1983 apud BA RBOSA et al . 1999), os profissionais de saúde se empenham pouco na orientação de pessoas surdas quanto a assuntos em saúde, logo isso pode refletir na falta de interesse dessa população em procurar com frequência o atendimento médico.

A falta de atenção dada a esse tema tem acarretado a exposição de jovens surdos a muitos riscos, como a ocorrência de gestações precoces ou o acometimento por DSTs, especialmente a AIDS, situando-se aí a importância dos profissionais de saúde, dos educadores e da própria família no sentido de proporcionar a informação necessária para que deficientes auditivos possam se prevenir deforma adequada contra esses riscos (SOARES; MOREIRA; MONTEIRO, 2008). Considerando quea maior partedas infecções por HIV ocorrena adolescência ou no início da idade adulta (JEOLÁ S; FERRA RI, 2002) e que a contaminação por DSTs pode constituir uma porta de entrada para o vírus da AIDS, acredita-se que o conhecimento a cerca das formas de transmissão do HIV e de outras DTSs influencie consideravelmente no comportamento sexual de adolescentes (TRAJMAN et al . 2003), reduzindo os riscos de contração dessas doenças.

Diante do exposto, nos propomos a realizar uma pesquisa com o objetivo deanalisar comparativamente o conhecimento de estudantes - portadores ou não deal guma deficiência auditiva- deuma escola pública sobreDST semétodos contraceptivos; e avaliar como esses dados podem repercutir na susceptibilidade decada um dos grupos a problemas como DST segravidez precocee/ ou indesejada, buscando comparar se os resultados encontrados convergem com a literatura. 


\section{Método}

Este estudo foi realizado com estudantes, portadores ou não de deficiência auditiva, de uma escola pública cearense de inclusão de surdos, com o intuito de avaliá-los quanto ao grau de informação sobre métodos contraceptivos e DSTs e comparar os resultados obtidos entre os que são ouvintes e os que são não-ouvintes a fim de perceber se real menteexistea disparidade deconhecimentos bási cos sobre o assunto citada na literatura (CHAVEIRO; BARBOSA, 2005; SANTOS, 2003).

O estudo feito foi do tipo transversal (descritivo), tendo como público alvo estudantes do Ensino Médio, divididos em salas de aula para ouvintes e nãoouvintes.

O questionário utilizado para pesquisa constava de uma parte inicial, reservada para identificação dos entrevistados (idade, sexo eestado civil). A seguir, havia questões que nos orientaram na descrição da vida sexual dos participantes, ondefoi questionado sobre sexarca, número de parceiros, frequência com que tem relações sexuais, número de abortos e número de filhos. Havia, ainda, perguntas nas quais buscamos analisar o conhecimento dos estudantes sobre AIDS/ DSTs: formas de contágio de DSTs - 5 perguntas; curabilidade da AIDS - 1 pergunta; reconhecimento de sinais e sintomas típicos de DSTs - 1 pergunta; e procura por assistência médica para si e para o parceiro, em caso de DSTs - 3 perguntas, totalizando-se, assim, 10 perguntas. Por último, os participantes foram questionados sobre a frequência com que vão ao médico e sobre a forma como acreditam ser o uso correto dos anticoncepcionais hormonais orais (ACO).

Esse questionário foi formulado pelos pesquisadores a partir da experiência do Núcleo em Saúde Reprodutiva da Maternidade Escola Assis Chateaubriand (MEAC), sob coordenação da Profa . Dra. Silvia Bomfim Hyppólito.

A amostra constituiu-se de 149 estudantes, sendo 98 (65,80\%) ouvintes e51 (34,20\%) não-ouvintes. Dentro do grupo de ouvintes, 70 eram do sexo feminino, enquanto dos não-ouvintes, 28 eram mulheres. A idade variou entre 15 e 50 anos, com média de 23 anos e desvio-padrão (DP) de 6,94. Entreos ouvintes, a média da idade foi de 22 anos com DP de 6,6, e entre os não-ouvintes foi de 25, DP de 7,2, p $<0,05$. Quanto a ter relações sexuais, $89,8 \%$ dos ouvintes afirmam já ter tido sua primeira relação, contra $47,1 \%$ dos não-ouvintes. A média de idade da sexarca foi de 16 anos entre os ouvintes, DP 3,69, e 19 entre os não-ouvintes, DP 5,14, p <0,05. (Tabela 1). 
Tabela 1 - Características da amostra estudada.

\begin{tabular}{|c|c|c|c|}
\hline & Ouvintes & Não-ouvintes & Total \\
\hline \multicolumn{4}{|l|}{ Sexo } \\
\hline Masculino & $28(28,6 \%)$ & $23(45,1 \%)$ & $51(34,2 \%)$ \\
\hline Feminino & $70(71,4 \%)$ & $28(54,9 \%)$ & $98(65,8 \%)$ \\
\hline \multirow[t]{2}{*}{ Total } & $98(100,0 \%)$ & $51(100,0 \%)$ & $149(100,0 \%)$ \\
\hline & Ouvintes & Não-ouvintes & valor de $P$ \\
\hline Média de idade & 22 & 25 & 0,01 \\
\hline Teve relação sexual & $88(89,8 \%)$ & $24(47,1 \%)$ & 0,0 \\
\hline Média de idade da sexarca & 16 & 19 & 0,01 \\
\hline
\end{tabular}

Os questionários foram preenchidos voluntariamente, ea identidade dos voluntários foi preservada. Para isso, eles assinaram, após leitura, um termo deconsentimento livreesclarecido, no qual havia o objetivo da pesquisa, deixando clara a facultatividade da partici pação na pesquisa ea garantia de anonimato. Uma cópia do termo ficou em poder do voluntário eoutra em posse do grupo de pesquisa.

Tivemos a nossa disposição, durante todo o processo, um tradutor para a linguagem de Libras, imprescindível no momento da apresentação e no esclarecimento das dúvidas dos estudantes.

Os dados coletados a partir do questionário foram analisados pelo programa Epil nfo eentrecruzados para construção detabelas egráficos, bem como cálculos de medida de tendência central (média, moda e mediana), de dispersão (desvio padrão evariância) e defrequência. $O$ val or deP foi considerado rel evante quando $<0,05$.

O estudo foi submetido à apreciação do Comitê de Ética em Pesquisa, tendo sido aprovado, conforme recomendado pela Resolução no 196/ 96 do Conselho Nacional de Saúde.

\section{Resultados}

Com relação ao planejamento familiar (Tabela 2), 25 ouvintes (25,5\%) e 13 não-ouvintes $(25,5 \%)$ afirmaram já ter engravidado ou engravidado alguém, $p<0,05$. Com relação ao uso correto do anticoncepcional oral, 82 ouvintes (83,7\%) e 24 não-ouvintes $(47,1 \%)$ responderam corretamente, sendo o dado estatisticamente significante. 
Tabela 2 - Resposta dos estudantes quanto a temas de planejamento familiar.

\begin{tabular}{|c|c|c|c|}
\hline & Ouvintes $(\mathbf{n}=98)$ & Não-ouvintes $(\mathbf{n}=\mathbf{5 1})$ & Valor de $p^{2}$ \\
\hline $\begin{array}{l}\text { Já engravidou ou engravidou } \\
\text { alguém? Resposta positiva }\end{array}$ & $25(25,5 \%)$ & $13(25,5 \%)$ & 0,01 \\
\hline $\begin{array}{c}\text { Frequência de relações } \\
\text { sexuais }\end{array}$ & $\begin{array}{r}\text { Três vezes por } \\
\text { semana }(25,4 \%)\end{array}$ & Raramente $(26,1 \%)$ & \\
\hline $\begin{array}{l}\text { Uso correto do } \\
\text { anticoncepcional oral }\end{array}$ & $82(83,7 \%)$ & $24(47,1 \%)$ & 0,0 \\
\hline
\end{tabular}

${ }^{1}$ Dados sobre a resposta mais frequente a esta pergunta. ${ }^{2}$ Teste do qui-quadrado.

Com relação à AIDS e DSTs (Tabela 3 ), 74,7\% dos ouvintes responderam que não existe cura para AIDS, contra 50,9\% dos não ouvintes ( $p<$ $0,05)$. Quanto à forma de transmissão do HIV e outras DSTs, 8 ouvintes $(8,1 \%)$ e 26 não ouvintes (50,9\%) responderam que beijo, abraço e aperto de mão podem transmiti-la, ( $p<0,05)$; em relação ao uso correto da camisinha, 91 (98,2\%) ouvintes e $22(43,1 \%)$ não ouvintes concordam que é uma forma de prevenir AIDS e outras DSTs; 28 (54,9\%) não-ouvintes responderam que o coito interrompido pode evitar estas doenças; e apenas 28 não-ouvintes (54,9\%) responderam que uso compartilhado de seringas aumenta o risco de contrair HIV, contra $93(94,9 \%)$ ouvintes.

Em relação ao conhecimento sobre DSTs (Tabela 3), 88 (89,8\%) ouvintes afirmaram que lesões ou sintomas típicos (verrugas, ardência, feridas e corrimento anormal em região genital) podem denotar alguma DST, enquanto $22(43,1 \%)$ não-ouvintes afirmaram o mesmo fato. Com relação à procura pelo profissional de saúde, 96 (97,9\%) ouvintes procurariam um em caso de alguma lesão típica de DST (corrimento vaginal diferente, presença de ulceração genital, vesículas, verrugas), contra apenas $24(47,1 \%)$ não ouvintes que fariam o mesmo, $p<0,05$. E se apresentassem estes tipos delesões, 96 (97,9\%) ouvintes consideram importante o parceiro procurar por um profissional de saúde, sendo que somente $22(43,1 \%)$ não ouvintes têm a mesma opinião, $p<0,05$.

Falando-se do contágio de DSTs, 4 (6,7\%) dos ouvintes afirmaram ter tido al guma DST eter feito tratamento, contra 27 não-ouvintes (52,9\%), comp < 0,05. 
Tabela 3 - Opinião dos entrevistados quanto a temas como AIDS e outras DST'S.

\begin{tabular}{|c|c|c|c|}
\hline & Ouvintes $(\mathbf{n}=98)$ & Não-ouvintes $(\mathbf{n}=\mathbf{5 1})$ & Valor de $p^{1}$ \\
\hline Acha que AIDS não tem cura & $73(74,7 \%)$ & $26(50,9 \%)$ & 0,01 \\
\hline \multicolumn{4}{|l|}{$\begin{array}{c}\text { Respostas referentes à } \\
\text { transmissão de DSTs/AIDS }\end{array}$} \\
\hline $\begin{array}{l}\text { Considera que beijo, abraço e } \\
\text { aperto de mão possa transmitir } \\
\text { HIV }\end{array}$ & $8(8,1 \%)$ & $26(50,9 \%)$ & 0,0 \\
\hline $\begin{array}{l}\text { Uso correto da camisinha previne } \\
\text { AIDS e outras DST's }\end{array}$ & $91(98,2 \%)$ & $22(43,1 \%)$ & 0,0 \\
\hline $\begin{array}{l}\text { Coito interrompido previne AIDS } \\
\text { e outras DST's }\end{array}$ & $14(14,3 \%)$ & $28(54,9 \%)$ & 0,0 \\
\hline $\begin{array}{l}\text { Uso correto do ACO previne } \\
\text { AIDS ou outras DST's }\end{array}$ & $8(8,1 \%)$ & $23(45,1 \%)$ & 0,0 \\
\hline $\begin{array}{l}\text { Uso compartilhado de seringas } \\
\text { aumenta o risco de contrair HIV }\end{array}$ & $93(94,9 \%)$ & $28(54,9 \%)$ & 0,0 \\
\hline \multicolumn{4}{|l|}{$\begin{array}{c}\text { Respostas referentes ao } \\
\text { conhecimento sintomático de } \\
\text { DSTs e à procura ao atendimento } \\
\text { médico } \\
\end{array}$} \\
\hline $\begin{array}{l}\text { Feridas, ardência, verrugas e } \\
\text { corrimento anormal em região } \\
\text { genital pode indicar DST's }\end{array}$ & $88(89,8 \%)$ & $22(43,1 \%)$ & 0,0 \\
\hline $\begin{array}{l}\text { Procuraria um profissional de } \\
\text { saúde se aparecesse alguma lesão } \\
\text { genital }\end{array}$ & $96(97,9 \%)$ & $24(47,1 \%)$ & 0,0 \\
\hline $\begin{array}{l}\text { Se diagnosticado DST, acha } \\
\text { importante parceiro procurar } \\
\text { profissional de saúde }\end{array}$ & $96(97,9 \%)$ & $22(43,1 \%)$ & 0,0 \\
\hline
\end{tabular}

${ }^{1}$ Teste do qui-quadrado.

Considerando o fato de acompanhamento médico, grande parte dos ouvintes vai ao médico anualmente (38,9\%), enquanto que a maioria dos nãoouvintes nunca foi ao médico (32,6\%), como se pode observar na Tabela 4.

Tabela 4 - Frequência do acompanhamento médico dos ouvintes e não-ouvintes.

\begin{tabular}{rccccc}
\hline & \multicolumn{2}{c}{ Ouvintes $(\boldsymbol{n}=\mathbf{9 8})$} & \multicolumn{2}{c}{ Não-ouvintes $(\boldsymbol{n}=\mathbf{5 1})$} \\
\cline { 2 - 5 } & Frequência & \% & Frequência & \% \\
\hline Mensalmente & 4 & $4,1 \%$ & Nenhum & $0,0 \%$ \\
Trimestralmente & 11 & $11,2 \%$ & 11 & $21,6 \%$ \\
Semestralmente & 16 & $16,3 \%$ & 4 & $7,8 \%$ \\
Anualmente & 38 & $38,8 \%$ & 10 & $19,6 \%$ \\
Raramente & 7 & $7,1 \%$ & 9 & $17,6 \%$ \\
Nuncafoi & 22 & $22,5 \%$ & 17 & $33,4 \%$ \\
\hline
\end{tabular}




\section{Dıscussão}

A análise das respostas dos estudantes às questões do questionário permitiu-nos tecer al gumas reflexões acerca da forma como têm sido repassadas a eles informações em saúde sexual e prevenção de gravidez precoce e DSTs. É interessante citar que no grupo há predominância de adultos jovens, faixa etária culturalmente mais vulnerável a práticas sexuais inseguras e, por conseguinte, a riscos por elas oferecidos (BENTO, 2000 apud BENTO, 2006).

A maioria dos ouvintes entrevistados (89,8\%), epouco menos da metade dos não-ouvintes (47,1\%), revelou que já possuíam vida sexual ativa. Dentro do grupo deouvintes, tal proporção era esperada, pois, conformeapontado na pesquisa Comportamento Sexual da População Brasileira e Percepções sobre o HIV/ AIDS (BRASIL, 2000), em 1998, 92,3\% dos jovens (homens e mulheres) de 20 a 24 anos já tinham tido relações sexuais, faixa etária em que se encontra maior parte dos ouvintes pesquisados. Quanto aos surdos, não encontramos, em nossa revisão bibliográfica, nenhum estudo no qual esse parâmetro tenha sido avaliado deforma isolada. Entretanto, a menor proporção denão-ouvintes em vida sexual ativa, aliada à sexarca média superior e à frequência de relações sexuais diminuída, quando comparadas aos respectivos valores encontrados em ouvintes (Tabelas 1 e 2), feznos inferir que os deficientes auditivos sofrem retardo no início da vida sexual, provavelmente devido aos tabus que permeiam os cotidianos desses jovens e lentificam, ou mesmo excluem, o entendimento da sexualidade como importante fator de desenvolvimento pessoal (MAIA, 2001).

A necessidade de mais informações sobre o assunto planejamento familiar, por partedo grupo de surdos, é notória. Na Tabela 2, por exemplo, 47,1\% desse grupo responderam corretamente sobre o uso de anticoncepcional hormonal oral (ACO), contra 83,7\% dos ouvintes que obtiveram êxito na resposta. Essefato é corroborado por Santose Shiratori (2004), quando afirmaram que 64\% deum grupo de surdos relataram ter necessidade de maiores esclarecimentos em planejamento familiar.

Quanto aos resultados obtidos nos questionamentos que buscavam avaliar o conhecimento dos estudantes em modos de transmissão e prevenção de DSTs, com enfoque especial na AIDS, encontramos que em todos os questionamentos (Tabela 3, respostas referentes à transmissão deDSTs/ AIDS), os ouvintes demonstraram ter maior conhecimento sobre o tema do que os nãoouvintes.

Ainda sobre o tópico de transmissão deDSTS/ AIDS, valedestacar que, para $56,9 \%$ dos não-ouvintes e $1,8 \%$ dos ouvintes, a camisinha não é um método adequado para prevenção de DSTs/ AIDS. Consideramos esse um achado crítico, uma vez que são insistentes as campanhas vinculadas em mídia aberta (tel evisão, rádio, revistas/ jornais e internet) trazendo informações acerca da importância do uso de preservativos na prevenção de DSTs e, principalmente, AIDS. Em 
contrapartida, para 45,1\% dos não-ouvintes e 8,1\% dos ouvintes o uso de ACO é uma opção segura para prevenção dessas doenças, assim como coito interrompido também éuma forma de proteção para $54,9 \%$ dos não-ouvintes e $14,3 \%$ dos ouvintes (Tabela 3). São, portanto, equívocos grosseiros, os quais facilmente poderiam ser esclarecidos caso houvesse uma orientação adequada.

Quanto às formas de contágio das DSTs e da AIDS (Tabela 3), destacamos achados não menos preocupantes, pois, dentre os não-ouvintes, 50,9\% acredita quebeijo, abraço eaperto de mão podem transmitir o HIV; e 44,1\% acredita que o compartilhamento de seringas não oferecer risco à contração do HIV. Respectivamente, encontramos as seguintes porcentagens no grupo de ouvintes: 8,1\%; e 5,1\%.

Diante do exposto, entendemos que os surdos detêm menos informações acerca das formas de transmissão de DSTs, conclusão semelhante à que chegou Barbosa et al. (1999). Além disso, essa carência informacional torna os deficientes auditivos mais susceptíveis à infecção por essas doenças (BARES 1992 apud PEINKOFER, 1994).

Foi evidenciado nas respostas dadas à questão que tratava sobre a possi bilidade de cura ou não da AIDS que 50,9\% dos não-ouvintes e $25,3 \%$ dos ouvintes consideram-na como uma doença curável (tabela 3). Consideramos esse índice bastante alto, principalmente o encontrado entre os ouvintes, pois teoricamente deveriam ser um grupo privilegiado quanto ao acesso às informações em saúdesexual, tão comumentedifundidas em mídia nacional. Quanto aos surdos, nosso achado corrobora com os obtidos por Bisol et al. (2008) em pesquisa semelhante, ratificando a idéia de que os deficientes auditivos detêm pouco conhecimento acerca da AIDS.

A conduta dos entrevistados diante da suspeita e do diagnóstico de umaDST, bem como quais sinais/ sintomas que para eles indicariam uma possível doença, foram também avaliados nesse estudo (tabela 3, respostas referentes ao conhecimento sintomático deDSTs eà procura ao atendimento médico). Obtivemos que $56,1 \%$ dos não-ouvintes não saberiam associar certos sinais esintomas (feridas, ardência, corrimento anormal everrugas na região genital) à possível contaminação por DST e que, mesmo na presença das referidas alterações, 52,9\% não procuraria um médico. Além disso, 56,9\% dos surdos responderam que, caso fossem diagnosticados com alguma DST, não achariam importante o parceiro procurar um médico.

Esses dados tornam evidente a necessidade de alertá-los sobre a importância não apenas dereconhecer al terações no corpo, mas também deprocurar tratamento médico tanto individual quanto para o parceiro (quando necessário) o mais breve possível. A baixa frequência deacompanhamento médico dessegrupo (33,4\% dos não-ouvintes nunca foi ao médico) pode estar relacionada à carência em detectar tais sinais esintomas característicos deDSTs, levando-os a não val orizar 
o surgimento de tais fatores e a não procurar assistência médica quando do aparecimento dos mesmos.

Evidenciamos, portanto, queinformações básicas relacionadas à forma detransmissão eprevenção deDSTs/ AIDS não estão atingindo a população surda de maneira eficaz, pois esbarram em limitações inerentes à própria deficiência ou que surgem em decorrência de falhas na educação dos surdos (MINTER, 1983; CURSINO et al.,2006; GUARINELLO, 2009).

\section{Conclusões}

A existência de uma legislação objetivando a integração dos deficientes auditivos à sociedade, teoricamente, deveria garantir a essegrupo um maior acesso à educação, facilitando, assim, a transmissão do conhecimento, especialmente aquele referente ao tema saúde. Ao longo do presente estudo, no entanto, percebemos que há uma enorme disparidade entre a teoria e a realidade do cotidiano demuitos deficientes auditivos no contexto da educação em saúdesexual, uma vez que, de acordo com os resultados obtidos, uma significativa parcela do grupo estudado não possui informações suficientes para garantir um comportamento sexual seguro que evite a infecção por DSTs.

Observamos que as barreiras da linguagem revelam-se como uma problemática que dificulta a comunicação entre os profissionais de saúde e os deficientes auditivos. Em nosso estudo, foi de grande valia a participação do interprete de Libras na realização da pesquisa e no esclarecimento de dúvidas dos surdos, o que ressal ta a importância desses profissionais na garantia do mel hor aproveitamento dos deficientes auditivos em quaisquer atividades em promoção de saúde a eles direcionadas.

Entendemos, assim, que algumas medidas poderiam ser tomadas com o intuito dereduzir o obstáculo da linguagem, proporcionando uma difusão mais eficaz de informações aos deficientes auditivos, principalmente sobre o tema saúde. A capacitação deprofissionais da saúdeedeprofessores deensino fundamental emédio, por exemplo, faz-se essencial para esse processo. A preparação desses profissionais, ainda na graduação, para comunicação em Libras, também seria de grande valia.

A lém disso, é fundamental a inclusão, no currículo escolar de escolas para deficientes auditivos, de disciplinas voltadas para a discussão de assuntos relacionados à sexualidade e à educação sexual; e a ampliação do espaço para discussão em outras instituições além da escola, como centros comunitários e o próprio meio familiar, facilitando a divulgação da informação mais rapidamente (BARBOSA et al., 1999; CURSINO et al., 2006; SOUZA; PAGLIUCA, 2002). Tais propostas garantiriam a melhoria do acesso desse grupo a informações imprescindíveis para a promoção e a prevenção da saúde, favorecendo a adoção de um comportamento sexual seguro, capaz de evitar gestações precoces e de impedir a contração de DSTs. 


\section{Referências}

BARBOSA, M.A. et al. Ensino esaúde: o que pensam eo que sabem os deficientes auditivos. Revista Eletrônica de Enfermagem, Goiânia, v. 1, n. 1, 1999. Disponível em: ‘http:/ / www.fen.ufg.br/ revista/ revistal_1/ Audi.html>. A cesso em: 6 jul. 2008.

BENTO, I.C.B.; BUENO, S.M.V. A AIDS sob a ótica do surdo adulto jovem. Jornal Brasileiro D oenças Sexualmente Transmissíveis, Rio de Janeiro, v.17, n.4, p. 288-294, 2005.

BENTO, I.C.B.; CARRARA, G.L.R.; PANTALEÃO, S.A. Orientação Sexual para Adolescentes: Sexo e Sexualidade o que São e Quais suas Conseqüências na A dolescência. Revista FA FIBE O n Line, Bebedouro, SP, n. 2, 2006. Disponível em: ‘http:/ / www.fafibe.br/ revistaonline/ arquivos/ isabel_orientacaosexual paraadolescentes.pdf $>$. A cesso em: 10 jul. 2008.

BISOL, C.A. etal. HIV/ AIDS knowledge and health-related attitudes and behaviors among deaf and hearing adolescents in southern Brazil. A merican A nnals of the D eaf, v. 153, n. 4, p. 349-356, 2008.

BRA SIL. Lei no 9.394, de 20 dezembro de 1996. Estabelece as diretrizes e bases da educação nacional. Disponível em: বhttp:/ / www.planalto.gov.br/ ccivil_03/ LEIS/ I9394.htm>. Acesso em: 16 fev. 2010.

BRASIL. Lei no 10.436, de 24 de abril de 2002. Dispõe sobre a Língua Brasileira de Sinais Libras edá outras providências. Disponível em: 〈http:/ / www.planalto.gov.br/ ccivil_03/ Leis/ 2002/ L10436.htm>. A cesso em: 16 fev. 2010.

BRASIL. Ministério da Educação. Secretaria de Educação Especial. Política N acional de Educação Especial na Perspectiva da E ducação Inclusiva. Brasília: MEC/ SEESP, 2007.

BRASIL. Ministério da Saúde (MS). Comportamento sexual da população brasileira e percepções do HIV/ AIDS. Série A valiação, Brasília, MS, n. 4, 2000.

CHAVEIRO, N.; BARBOSA, M.A. Assistência ao surdo na área de saúde como fator de inclusão social. Revista da Escola de Enfermagem da U SP, São Paulo, v. 39, n. 4, p. 417-422, 2005.

CURSINO, H.M. et al. Orientação sexual para jovens adultos com deficiência auditiva. Revista Brasileira de E ducação Especial, Marília, v. 12, n. 1, p. 29-48, 2006.

GASKINS, S. Special Population: HIV/ AIDSA mong the Deaf and Hard of Hearing. Journal of the A ssociation of N urses in AID S care, v. 10, n. 2, p. 75-78, mar/ abr 1999.

GUARINELLO, A.C. et al. Surdez e letramento: pesquisa com surdos universitários de Curitiba e Florianópolis. Revista Brasileira de Educação Especial, Marília, v. 15, n. 1, p. 99120, 2009.

Instituto Brasileiro de Geografia e Estatística. Censo demográfico, Rio de Janeiro, p. 1-178, 2000.

JEOLAS, L.S; FERRARI, R.A.P. Oficinas de prevenção em um serviço de saúde para adolescentes: espaço de reflexão edeconhecimento compartilhado. Ciência \& SaúdeC ol etiva, Rio de Janeiro, v. 8, n. 2, p.611-620, 2003.

MAIA, A.C.B. Reflexões sobrea educação sexual da pessoa com deficiência. Revista Brasileira de Educação Especial. Marília, v. 7, n. 1, p.35-46, 2001. 
MAZZOTTA, M.J.S. E ducação especial no Brasil: história epolíticas públicas. São Paulo: Cortez, 1996.

MINTER, $M$. The status of health education and sex education programs for the deaf what implications does this have for health educators? R eports D escriptive, v. 141, p. 8, 1983.

OMS. Deafnessand hearing impairment. Mar. 2006. Disponível em: <http:/ / www.who.int/ mediacentre/ factsheets/ fs300/ en/ print.html >. A cesso em: 15 fev. 2010.

PEINKOFER, J.R. HIV education for the deaf, a vulnerable minority. Public $\mathrm{H}$ ealth $\mathrm{R}$ eports, v. 109, n. 3, p. 390-396, 1994.

SANTOS, E.M.; SHIRATORI, K. Asnecessidades desaúdeno mundo do silêncio: um diálogo com os surdos. Revista Eletrônica de Enfermagem, v. 6, n. 1, 2004. Disponível em: <http:/ / www.fen.ufg.br/ revista/ revista6_1/ f7_surdos.html >. A cesso em: 19 jan. 2010.

SANTOS, M.P. A formação de professores no contexto da inclusão. In: CONGRESSO INTERN ACIONAL DO INES, 2, 2003, Rio deJaneiro. A nais... Rio deJaneiro: INES; 2003, p.65.

SOARES, A.H.R.; MOREIRA, M.C.N.; MONTEIRO, L.M.C. Jovens portadores de deficiência: sexualidade e estigma. Ciência \& Saúde Coletiva, Rio de Janeiro, v. 13, n. 1, p. 185-194, 2008.

SOUZA, R.A.; PAGLIUCA, L.M.F. Educação em saúde como fator de participação da enfermeira na construção da cidadania do surdo: reflexão crítica. Escola A nna N ery R evista de Enfermagem, Rio de Janeiro, v. 6, n. 3, p. 489-497, 2002.

TRAJMAN, A. et al . Knowledge about STD/ AIDS and sexual behavior among high school students in Rio de Janeiro, Brazil. Caderno de Saúde Pública, Rio de Janeiro, v. 19, n. 1, p. 127-133, 2003.

Recebido em: 14/ 09/ 2009

Reformulado em: 22/ 02/2010

A provado em: 05/ 03/ 2010 


\section{ANEXO 1: QUESTIONÁRIO}

1. Qual o seu sexo?

( ) Feminino

( ) Masculino

2. Qual a sua idade?

3. Qual o seu estado civil?

( ) Solteiro(a)

( ) Casado(a)

( ) Separado(a)

( ) Viúvo(a)

( ) Outro. Qual?

4. Você já teve alguma relação sexual?

( ) $\mathrm{Sim}$

( ) Não

5. Se já teve alguma relação sexual, foi com quantos anos?

6. Você já engravidou ou engravidou alguém?

( ) $\mathrm{Sim}$ ( ) Não

7. Você já abortou?

( ) Sim

( ) Não

8. Se você já abortou, o aborto foi:

( ) Natural

( ) Provocado

9. Você tem filhos?

( ) Sim. Quantos?

( ) Não

10. Você já teve alguma DST?

( ) Sim, mas já fiz o tratamento.

( ) Sim, mas ainda não fiz o tratamento.

( ) Não
11. Qual a frequência com que você tem atividade sexual?

( ) três ou mais vezes por semana

( ) 1 ou 2 vezes por semana

( ) uma vez por mês

( ) uma vez por ano

( ) não me lembro quando foi a última vez

12. Quantos parceiros você tem atualmente?

( ) Não tenho parceiro atualmente.

( ) Um

( ) Dois

( ) Três

( ) Outro. Quantos?

13. Qual a frequência que você vai ao médico?

( ) uma vez a cada seis meses

( ) uma vez ao ano

( ) uma vez a cada dois anos

( ) raramente vou ao médico

14. Você acha que a AIDS tem cura?
( ) $\mathrm{Sim}$
( ) Não

15. Você acha que beijo, abraço, e aperto de mão pode transmitir AIDS?

( ) $\mathrm{Sim}$

( ) Não

16. O uso correto do preservativo (camisinha) evita AIDS e outras DST?

( ) Sim

( ) Não

17. Quando o homem ejacula fora evita AIDS e outras DST?
( ) $\mathrm{Sim}$
( ) Não

18. O uso correto de anticoncepcional oral evita AIDS ou DST?

( ) $\mathrm{Sim}$

( ) Não

19. O uso compartilhado de agulhas e seringas transmite AIDS?

( ) $\mathrm{Sim}$

( ) Não

20. Como você acha que deve ser o uso correto do anticoncepcional oral

( ) somente antes da relação sexual

( ) diariamente, com intervalo de 7 dias entre as caixas

21. O aparecimento de feridas, corrimentos anormais, verrugas e ardência podem indicar DST?

( ) $\mathrm{Sim}$

( ) Não

22. Se aparecesse algumas das alterações citadas anteriormente, você procuraria um médico?

( ) $\mathrm{Sim}$

( ) Não

23. Se você fosse diagnosticado(a) com alguma DST, acha importante seu parceira(o) procurar um médico?

( ) $\mathrm{Sim}$

( ) Não 